\title{
Assessment of knowledge and attitude and practice towards malignant hypertension among interns in Saudi Arabia, 2018
}

Majed Meshal H Almutairi ${ }^{1}$, Muhammad Abdullah M Almalki ${ }^{2}$, Abdulrahman Bader A Alaql ${ }^{3}$ 1-Imam Mohammad Bin Saud University 2-Northen Border University 3-Prince Sattam Bin Abdulaziz University

\begin{abstract}
$\underline{\text { Abstract }}$
Background: Malignant hypertension (MHT) is the most severe form of arterial hypertension.

Objectives: Assessing the knowledge, attitude and practice (KAP) regarding the malignant hypertension in Kingdom of Saudi Arabia (KSA). Methods: A cross-sectional questionnaire based study was conducted at 26 different hospitals in Saudi Arabia, Ministry of Health, from March to July 2018 among 260 interns. Results: This study showed a high level of knowledge and awareness among the respondent's regarding the malignant hypertension definition, cut off values, diagnosis, symptoms and treatment. The prompt knowledge was reflected by good attitude and practice among most of the interns. Most of the interns knew the definition of malignant hypertension, and the blood pressure values of hypertensive subjects without comorbidities, the difficulty in diagnosis of malignant hypertension and the importance of monitoring the blood pressure if suspecting malignant hypertension. Also, most of them showed good awareness of the targeted BP that would like to be achieved in hypertensive patients with diabetes mellitus and/or chronic kidney disease without proteinuria (87.5\%). Conclusion: The level of knowledge was sufficient among interns in KSA. Interns' knowledge about malignant hypertension is reflected in their attitude and practice.
\end{abstract}

Keywords: Knowledge, Attitude, Practice, Interns, Malignant Hypertension, KSA

\section{Background}

Hypertension is a major cardiovascular risk factor. Malignant hypertension (MHT) is defined as extreme elevation of blood pressure (diastolic above $130 \mathrm{~mm} \mathrm{Hg}$ ) that could be associated with either hemorrhage or exudates from the retina that may be accompanied by papilledema or not. It is also known as accelerated hypertension and is considered as the most severe form of hypertension or emergency hypertension $^{(\mathbf{1}, 2)}$.

About $26.4 \%$ of adults around the world were diagnosed to suffer from hypertension in 2000, however in 2025 it is expected to reach to $60 \%$ of the globe adults (3). The actual prevalence of malignant hypertension is still a debate however the in UK one or two new cases per 100 thousand subjects are diagnosed with MHT every year ${ }^{(4,}$ 5). Also, the number of new cases hasn't been changed for long time and its prevalence is still low ${ }^{(6)}$. There are a vast range of available antihypertensive drugs that can be used for management of hypertension, although MHT is still a major obstacle for physicians to diagnose and manage ${ }^{(7,8)}$.

The diagnosis of MHT is challenging as the symptoms can only be established after occurrence of organ damage hence retrospective diagnosis is difficult. Another obstacle for MHT diagnosis is that the retinopathy associated with malignant hypertensive can gradually resolve during a short period thus it is hard to be diagnosed ${ }^{(9)}$.

Although being more worldwide prevalent, the prognosis of MHT was improved during the last decades especially in developed countries. The poor prognosis could occur if no treatment or management resulting in persistent target organ damage and other coronary complications ${ }^{\mathbf{1 0}, \mathbf{1 1}}$.

\section{Methods:}

Study design: A cross-sectional questionnaire based study was conducted at Saudi Arabia, from March to July 2018.

\section{Study population and sample size:}

In the first stage of selection, a stratified random sampling was used to select Saudi females randomly out of thirteen governorates in Saudi Arabia according to their population density in the different regions. The second stage of selection included random selection of 2 hospitals from each governorate and then 10 interns were randomly selected from each hospital. Thus the final sample size included 260 interns from different 26 hospitals randomly selected in KSA. 


\section{Study tools:}

The questionnaire was designed after conducting a systemic search, which was done using medical search engines using the following keywords: knowledge, attitude and practice, interns, KSA, Hypertension. The questionnaire was then based on some previous study with some modifications ${ }^{(\mathbf{1 2}, \mathbf{1 3})}$. It was reviewed by 3 experts to be validated. The questionnaire consisted of 3 parts that concerns the questions related to knowledge, attitude and practice of interns.

\section{Ethical approval:}

The study approval was handed from the ethical committee and institutional review board of Faculty of Medicine. All the included interns gave a written informed consent for approval on taking part in the study.

\section{Statistical analysis:}

The data administration was done using the Statistical Package for Social Sciences (SPSS, version 22) for windows. Results are represented as numbers and frequencies (\%).

\section{Results:}

\section{Assessment of knowledge regarding malignant hypertension among interns:}

Table 1 shows the awareness of interns regarding malignant hypertension. All the respondents answered the nine questions and the majority of them showed good knowledge as all of them knew the definition of malignant hypertension, and the blood pressure values of hypertensive subjects without comorbidities, the difficulty in diagnosis of malignant hypertension and the importance of monitoring the blood pressure if suspecting malignant hypertension. Also, most of them showed good awareness of the targeted BP that would like to be achieved in hypertensive patients with diabetes mellitus and/or chronic kidney disease without proteinuria (87.5) and $69.2 \%$ knew about the maximum observational period for a patient recently diagnosed with stage 1 hypertension having no evident target organ involvement and any additional risk factor. As for the average period of malignant hypertension, a good level of knowledge was found among $67.7 \%$ of interns while $91.9 \%$ showed perfect knowledge of the histological features suspected for malignant hypertension diagnosis. The knowledge regarding the complications of MHT was fair among 81.2\% of interns.

Table (1): Awareness of interns regarding malignant hypertension:

\begin{tabular}{|c|c|c|}
\hline & Correct & Incorrect \\
\hline $\begin{array}{l}\text { 1- What is the blood pressure (BP) values defines hypertension } \\
\text { in an adult subject without comorbidities? }\end{array}$ & $\begin{array}{c}260 \\
(100 \%)\end{array}$ & $\begin{array}{c}0 \\
(0 \%)\end{array}$ \\
\hline $\begin{array}{l}\text { 2- What is the target BP you would like to achieve in } \\
\text { hypertensive patients with diabetes mellitus and/or chronic } \\
\text { kidney disease without proteinuria? }\end{array}$ & $\begin{array}{c}204 \\
(78.5 \%)\end{array}$ & $\begin{array}{c}56 \\
(21.5 \%)\end{array}$ \\
\hline $\begin{array}{l}\text { 3- What is the maximum observational period for a patient } \\
\text { recently diagnosed with Stage } 1 \text { hypertension having no } \\
\text { evident target organ involvement and any additional risk } \\
\text { factor? }\end{array}$ & $\begin{array}{c}180 \\
(69.2 \%)\end{array}$ & $\begin{array}{c}80 \\
(30.8 \%)\end{array}$ \\
\hline $\begin{array}{l}\text { 4- Malignant or accelerated hypertension is defined clinically } \\
\text { by very high blood pressure (diastolic above } 130 \mathrm{~mm} \mathrm{Hg} \text { ) } \\
\text { accompanied by bilateral retinal hemorrhages and/or } \\
\text { exudates, with or without papilledema }\end{array}$ & $\begin{array}{c}260 \\
(100 \%)\end{array}$ & $\begin{array}{c}0 \\
(0 \%)\end{array}$ \\
\hline 5- The average of the malignant phase may last to $2-3$ months & $\begin{array}{c}176 \\
(67.7 \%)\end{array}$ & $\begin{array}{c}84 \\
(32.3 \%)\end{array}$ \\
\hline $\begin{array}{l}\text { 6- The main histological feature of malignant hypertension is } \\
\text { fibrinoid necrosis of arterioles in various tissues, including } \\
\text { the kidney, accompanied by proliferative endarteritis in } \\
\text { renal interlobular arteries }\end{array}$ & $\begin{array}{c}239 \\
(91.9 \%)\end{array}$ & $\begin{array}{c}21 \\
(8.1 \%)\end{array}$ \\
\hline $\begin{array}{l}\text { 7- The presentation and diagnosis of malignant hypertension is } \\
\text { often delayed due to developing clinical symptoms only at a } \\
\text { later stage of disease. }\end{array}$ & $\begin{array}{c}260 \\
(100 \%)\end{array}$ & $\begin{array}{c}0 \\
(0 \%)\end{array}$ \\
\hline $\begin{array}{l}\text { 8- The patients must be monitored and followed up until blood } \\
\text { pressure decreases }\end{array}$ & $\begin{array}{c}260 \\
(100 \%)\end{array}$ & $\begin{array}{c}0 \\
(0 \%)\end{array}$ \\
\hline $\begin{array}{l}\text { 9- MHT is associated with severe complication and organ } \\
\text { damage including kidney and brain damage }\end{array}$ & $\begin{array}{c}211 \\
(81.2 \%)\end{array}$ & $\begin{array}{c}49 \\
(18.8 \%)\end{array}$ \\
\hline
\end{tabular}




\section{Level of knowledge:}

The level of knowledge was found to be good among the majority of interns (80.4\%) and was insufficient among $19.6 \%$ of them (Table 2).

Table (2): Interns' level of knowledge

\begin{tabular}{|ll|c|c|}
\hline Knowledge level & Frequency & Percent (\%) \\
\hline & Good (5-9) & 209 & 80.4 \\
& Poor (0-4) & 51 & 19.6 \\
& Total & 260 & 100.0 \\
\hline
\end{tabular}

- Evaluating the interns' attitude: The attitude of the subjects towards malignant hypertension was good among most of them as all of them would check the patient's history before diagnosing MHT. Also, 65.8\% of them consider retinopathy with hypertension is evidence for needing emergency and $78.1 \%$ would check the vital organs if suspect MHT (Table 3).

Table (3): Attitude of interns toward malignant hypertension $(n=260)$

\begin{tabular}{l}
$\begin{array}{l}\text { Physician should always check the history of the patient to } \\
\text { diagnose MHTN }\end{array}$ \\
\hline Agree \\
\hline Disagree
\end{tabular}

\section{Practice pattern of included subjects:}

Table 4 indicated the practice pattern among the included subjects regarding malignant hypertension. All the participants usually check blood pressure if the patient is presented with headache, numbness, blurred vision or changes in mental status and consider MTH as an emergency that need follow up. Also, 92.7\% physically examine the patient for leg swelling, fluids in lung, abnormal heart sounds, and retinal changes. About $73.1 \%$ would do chest X-ray and kidney profile for better diagnosis of malignant hypertension.

Table (4): Practice pattern among interns:

\begin{tabular}{|c|c|c|}
\hline & Yes & No \\
\hline $\begin{array}{l}\text { 1. I usually check the blood pressure if the patient is } \\
\text { presented with headache, numbness, blurred vision or } \\
\text { changes in mental status. }\end{array}$ & $260(100 \%)$ & $(0 \%)$ \\
\hline $\begin{array}{l}\text { 2. I should physically examine the patient for leg swelling, } \\
\text { fluids in lung, abnormal heart sounds, and retinal } \\
\text { changes }\end{array}$ & $241(92.7 \%)$ & $19 \quad(7.3 \%)$ \\
\hline $\begin{array}{l}\text { 3. Chest X-ray and kidney profile analysis must be } \\
\text { conducted }\end{array}$ & $190(73.1 \%)$ & $70 \quad(26.9 \%)$ \\
\hline $\begin{array}{l}\text { 4. I consider MHTN as emergency and follow up the patient } \\
\text { till the blood pressure decreases }\end{array}$ & $260(100 \%)$ & $0(0 \%)$ \\
\hline
\end{tabular}




\section{Discussion}

Controlling malignant hypertension is a significant challenge as it is considered as a chief etiology of heart diseases and death among adults ${ }^{(\mathbf{1 4}, \mathbf{1 5})}$. The inability of physicians and health care providers to deliver proper controlling over hypertension can result in poor BP maintenance among hypertensive patients resulting in longevity complications and high rates of death ${ }^{(16-18)}$. In KSA, no known studies in the literature have investigated the knowledge and practice patterns of interns regarding malignant hypertension.

Many studies have shown improper diagnosis of hypertension and its complications with poor control around the world and especially the majority of developing countries ${ }^{(19,20)}$.

This study showed a high level of knowledge and awareness among the respondent's regarding the malignant hypertension definition, cut off values, diagnosis, symptoms and treatment. The prompt knowledge was reflected by good attitude and practice among most of the interns. Thus many studies focuses on the importance of diagnosing hypertension to control the potentially detrimental complications that could arouse if hypertension improperly diagnosed or untreated $^{(21)}$. Malignant hypertension remains asymptomatic till a late course that may result in organ damage. The result of our study showed an adequate level of awareness of diagnosis, work up and management of malignant hypertension. However, these results were in contrast with other studies showing low level of knowledge among doctors and physicians ${ }^{(12,13,22)}$.

Most of the interns knew the definition of malignant hypertension, and the blood pressure values of hypertensive subjects without comorbidities, the difficulty in diagnosis of malignant hypertension and the importance of monitoring the blood pressure if suspecting malignant hypertension. Also, most of them showed good awareness of the targeted BP that would like to be achieved in hypertensive patients with diabetes mellitus and/or chronic kidney disease without proteinuria (87.5). Recently, most of the physicians from Pakistan $(74.5 \%)$ knew the cut off level of blood pressure to define hypertension in an otherwise healthy person ${ }^{(22)}$ however only $42.9 \%$ knew the cut off level to define hypertension in the presence of co- morbidities such as diabetes and/or chronic kidney disease. Also, the cut off level knowledge was proper among 70-90\% of Polish medical students ${ }^{(23)}$. Another consistent study in Jordan presented that $66.2 \%$ had proper awareness of the cut off level of blood pressure in individuals lacking diabetes mellitus and $75.9 \%$ knew the levels for those with diabetes and/or chronic kidney disease ${ }^{(24)}$. The level of practice was good among most of the participants and this could be attributed to that the level of awareness was very high among most of the participants and this study was the first study showing higher rates of knowledge among interns.

This study has some limitations including that lack of available data regarding malignant hypertension knowledge. Another limitation is that this study didn't compare the knowledge of interns with physicians regarding hypertension.

\section{Conclusion:}

The level of knowledge was sufficient among interns in KSA. Interns' knowledge about malignant hypertension is reflected in their attitude and practice.

\section{References:}

1.Shantsila A, Shantsila E and Lip GY (2010): Malignant hypertension: a rare problem or is it underdiagnosed? Current vascular pharmacology, 8:775-779.

2.Shantsila A and Lip GYH (2017): Malignant Hypertension Revisited-Does This Still Exist? American journal of hypertension, 30:543-549.

3.Kearney PM, Whelton M, Reynolds, et al. (2005): Global burden of hypertension: analysis of worldwide data. Lancet, 365:217223.

4.Lip GY, Beevers M and Beevers G (1994): The failure of malignant hypertension to decline: a survey of 24 years' experience in a multiracial population in England. Journal of hypertension, 12:1297-1305.

5.Lane DA, Lip GY and Beevers DG (2009): Improving survival of malignant hypertension patients over 40 years. American journal of hypertension, 22:1199-1204.

6.Polgreen LA, Suneja M, Tang F et al. (2015): Increasing trend in admissions for malignant hypertension and hypertensive encephalopathy in the United States. Hypertension, 65:1002-1007.

7.Cremer A, Amraoui F, Lip GYH et al. (2015): From malignant hypertension to 
hypertension-MOD: a modern definition for an old but still dangerous emergency. Journal Of Human Hypertension, 30:463.

8.Phan DG, Dreyfuss-Tubiana $\mathrm{C}$ and Blacher J (2015): Hypertensive emergencies and urgencies. Presse medicale, 44:737-744.

9.Bortolotto LA, Cesena FH, Jatene F et al. (2003): Malignant hypertension and hypertensive encephalopathy in primary aldosteronism caused by adrenal adenoma. Arquivos brasileiros de cardiologia, 81:97100.

10.Sevillano AM, Cabrera J, Gutierrez E et al. (2015): Malignant hypertension: a type of IgA nephropathy manifestation with poor prognosis. Nefrologia : publicacion oficial de la Sociedad Espanola Nefrologia, 35:42-49.

11.Januszewicz A, Guzik T, Prejbisz A et al. (2016): Malignant hypertension: new aspects of an old clinical entity. Polskie Archiwum Medycyny Wewnetrznej, 126:86-93.

12.Ahmad N and Khan AH (2018): Doctors' Knowledge of Hypertension Guidelines Recommendations Reflected in Their Practice. International journal of hypertension, 2018:8524063.

13.Noubiap JJN, Jingi AM, Veigne SW et al. (2014): Approach to hypertension among primary care physicians in the West Region of Cameroon: substantial room for improvement. Cardiovascular Diagnosis and Therapy, 4:357364.

14.Amraoui F, Van Der Hoeven NV, Van Valkengoed IG et al. (2014): Mortality and cardiovascular risk in patients with a history of malignant hypertension: a case-control study. Journal of clinical hypertension ,16:122-126.

15.van der $M$ and van der $M$ (2013): Malignant hypertension: a preventable emergency. The New Zealand medical journal, 126:39-45.

16.Parker A, Nagar B, Thomas G et al. (2011): Health practitioners' state of knowledge and challenges to effective management of hypertension at primary level. Cardiovasc J Afr., 22:186-190.

17.Tocci G, Ferrucci A, Pontremoli R et al. (2015): Blood pressure levels and control in
Italy: comprehensive analysis of clinical data from 2000-2005 and 2005-2011 hypertension surveys. Journal of human hypertension, 29:696-701.

18.Tocci G, Borghi C and Volpe M (2014): Clinical management of patients with hypertension and high cardiovascular risk: main results of an Italian survey on blood pressure control. High blood pressure \& cardiovascular prevention : the official journal of the Italian Society of Hypertension, 21:107117.

19.Chow CK, Teo KK, Rangarajan $S$ et al. (2013): Prevalence, awareness, treatment, and control of hypertension in rural and urban communities in high-, middle-, and lowincome countries. Jama., 310:959-968.

20.Lloyd-Sherlock $P$, Beard J, Minicuci $N$ et al. (2014): Hypertension among older adults in low- and middle-income countries: prevalence, awareness and control. Int J Epidemiol., 43:116-128.

21.Cuspidi C, Michev I, Meani S et al. (2003): Awareness of hypertension guidelines in primary care: results of a regionwide survey in Italy. Journal of human hypertension, 17:541-547.

22.Rehman A, Rehman T, Shaikh MA et al. (2011): Awareness of hypertension among the medical students and junior doctors--a multicenter study from Pakistan. JPMA The Journal of the Pakistan Medical Association, 61:1153-1157.

23. Wizner B, Gryglewska B, Kocemba $\mathrm{J}$ et al. (2003): Knowledge of hypertension and blood pressure measurement procedure among students of last year of medical school in Cracow. Przeglad lekarski, 60:508-511.

24.Al-Azzam SI, Najjar RB and Khader YS (2007): Awareness of physicians in Jordan about the treatment of high blood pressure according to the seventh report of the Joint National Committee (JNC VII). European journal of cardiovascular nursing : journal of the Working Group on Cardiovascular Nursing of the European Society of Cardiology, 6:223232. 